\title{
RESEARCH INTO LABOUR, EMPLOYMENT AND WORK IN NEW ZEALAND: AN OVERVIEW
}

\author{
Philip S. Morrison
}

Victoria University of Wellington

\begin{abstract}
The purpose of this overview is to take stock of the research into labour, employment and work undertaken in New Zealand as represented by this conference and to summarise as succinctly as possible the key points made in each paper. The interpretation of what is important is inevitably subjective and while I'm sure most authors would concur with my reading there is undoubtedly room for discussion. The point however is to get the issues on the table so that some sense of collective progress can be identified. Existing gaps in the research we hope will be picked up and addressed at the eighth conference on Labour, Employment and Work to be held at Victoria University of Wellington in November 1998.
\end{abstract}

Gaps in research are particularly hard to identify even though each author has been asked to point out issues requiring further research. A reading of these 'Future Research' sections of the following papers together with my own sense of what is going on lead to the following thoughts. The first is the need to better understand why so many men of working age are not engaged in paid work in New Zealand and why so many of them are still not registered as unemployed. We need to know more about the increased polarisation between work 'rich' who have several in fulltime paid work and work 'poor' families who have none. We still do not have a good handle - conceptually or empirically - on the job market for the less skilled and those who engage the market infrequently and intermittently including those engaged in so called 'casual' work.

There is still a great deal to learn about regional labour markets and why they appear behave differently and the implications these differences have for uneven rates of labour market integration of populations across the country. Similarly there is much to be learned about employment within small businesses together with related issues of contracts, conflict and resolutions.

Another aspect that has not been investigated in New Zealand largely because of the lack of longitudinal surveys are the patterns apparent from individual's lifetime participation: in employment, unemployment, non-participation in the labour force and their associated income and earnings profiles. Although we now have a better idea of the pattern of flows across various states of the labour market there remain few if any examples of cases where researchers have tracked individual's labour market activity and income experiences over shorter time periods to look at the patterns of mobility and to assess the extent to which some people are persistently in states of disadvantage (e.g. unemployment, transient employment, low pay and poverty). Constructing such histories over a period of radical economic restructuring, internationalisation of the New Zealand economy and rapid technological change would make fascinating and instructive reading.

There is also a growing need to know more about the transmission of educational, employment and income levels between generations. Strategically targetted longitudinal surveys could go a longway to our better understanding of this critical end of labour market behaviour. The attention Statistics New Zealand is now beginning to pay to such surveys is therefore most welcome.

It is interesting that so few of the papers presented at this conference address the labour market from a macro perspective. This is a crucial context within which much of the subnational and micro research takes place. Research on New Zealand's slow growth in real individual and household incomes, on the level of aggregate unemployment and the factors that influence it as well as the impact of monetary and fiscal policies on employment and unemployment all deserve continuing attention.

While focus on individuals continues to be valuable there is also an ongoing need for greater attention to the workplace and to practices of industrial relations/human resource management practices requiring data collected from both management and employee representatives. How competent are New Zealand's business managers and what is the capacity of management alone or the organisation and its capacity for learning? Any focus on labour, employment and work begs questions about the organisation context and management contexts within which employment takes place.

Related to the above questions are those practices within organisations that may be elevating the status of Maori, ethnic minorities and women. In which organisations is this occuring, to what degree and where do these developments remain unobserved?

At the international level we still have very few studies 
which attempt to link developments in the international economy with changes in the domestic demand for labour, particularly different kinds of labour in different industries and locations.

The evidence on the impacts of the Employment Contracts Act are still quite unclear despite the substantial amount of work undertaken. Certainly, work on labour productivity, its measurement and analysis of developments across the economy emerges as an important priority. While most of the attention has been focussed on this particular act, there are other major changes whose impact also deserves the attention of New Zealand researchers: changes in training, skill qualifications and occupational safety and health (OSH) and accident insurance merit for example.

At the same time it is encouraging to see so many young scholars taking the opportunity to present in this conference series - getting feedback on their work and establishing networks and forging future employment connections. Of the forty five authors involved in the thirty five papers presented in November 1996, the largest single group (19) were fulltime University staff. A further eight were $\mathrm{PhD}$ candidates. Seven were from the public sector and 4 from the private sector. The remainder were research assistants (at Universities), practitioners and there was one masters student.

Finally there is the question of funding research into labour, employment and work. What is interesting about the present set of papers is how few actually cite explicit funding and we must assume that the costs of such research is absorbed within the general costs, mainly of Universities. And where funding is cited explicitly remarkably little appears to have come from the Foundation for Research, Science and Technology (FRST). Perhaps it is time for researchers in this field to form the kinds of research teams focussing on critical issues that we are seeing in other fields.

For the purpose of these proceedings the 35 papers have been grouped under nine headings. This overview comments briefly on the content of each of the papers beginning with an overview of recent developments in the New Zealand abour market.

\section{Overview and international comparisons}

One of the purposes of this series of conferences is to encourage the research community to continue monitoring changes in the New Zealand labour market. In this respect David Mare's paper on Labour market trends and outlook is particularly helpful. If one looks at the period 1991-1996, the increases in employment and work force participation both fulltime and part-time and corresponding reduction in unemployment look impressive. However when the whole decade prior to 1996 is examined the picture is less rosy: growth rates for employment, wages, and participation were all quite low. The particular time period one takes is therefore quite critical to the kind of conclusions drawn.

So what changed between 1991 and 1996? Maybe poor output and employment performance in the late 1980s and early 1990s was a temporary departure from long term growth trends. Its hard to separate the structural from the cyclical shifts that have occurred and to disentangle international from domestic influences. What is clear is that there remains considerable persistence in relative unemployment rates. The fact that the proportion underemployed for six months or more remains higher than in 1986 despite the rapid economic growth through 1996 suggests that job growth alone may have diminishing impact on the long term unemployed. Also, despite employment growth flows onto the unemployment register continue to rise.

Although all major demographic groups benefited from the recovery of $1991-1996$, the stark differences between the groups remain. Labour market conditions continue to deeply affect the lives of many of those with low education and lack of work experience. That a disproportionate number remain young, Maori and Pacific Island Polynesian continues to underscore the need to continue to monitor the social as well as economic consequences for this group.

What is critical to the long term health of the New Zealand economy is growth in labour productivity and this is clearly an area in which more research is needed. As Mare points out, New Zealand's historical rate of productivity growth has been poor and, at least on available evidence, does not appear to have been altered by developments over the last decade.

One of the enduring criticisms of employment policy in New Zealand has been the perceived negative effects on employment of Reserve Bank controls on the inflation rate. In one of the few papers which deals with this aspect of New Zealand's macro performance Simon Chapple addresses Larry Ball's work on OECD countries. This hows that countries with the large and lasting disinflations during the 1980 s had the largest rises in their equilibrium unemployment and benefit duration rates and the most marked falls in their labour force participation rates. Chapple confirms these results with his own analysis of the international data. Far from unemployment rates returning to 'normal' after the application of disinflationary instruments, conditions such as long term unemployment remained high even after several years of sustained economic growth. His analysis underscores the value of international comparative work for understanding the New Zealand experience.

\section{Increasing income inequalities}

It is not just the long term unemployed who appear relatively disadvantaged by employment policies based on economic growth alone; work in the UK and USA suggests a considerable loss of middle income earners to the poles of the income distribution. Until Sylvia Dixon's work there was little clear evidence for what had happened to individuals in New Zealand over the last decade although growing inequality in household incomes had already been documented. What is surprising about Dixon's results is that the aggregate hourly earnings distribution widened so little given the substantial economic and regulatory reforms im- 
plemented in New Zealand over the period. Using data from the Household Labour Force Survey Dixon found only a slight increase in hourly earnings inequality among males over the period of prolonged recession 1984 to 1995 although this did increase from 1988 onwards.

The small net growth in inequality however masks more significant changes within certain groups. There was also a widening gap between the relative earnings of educated and less educated workers in New Zealand, a pattern which mirrors the OECD experience. However the less-skilled and less-education workers in New Zealand did not experience substantial reductions in their relative earnings as the case in the USA or UK partly, Dixon suggests, because of a strong growth in demand for both the less skilled and highly skilled workers in the 1990s. At the same time many less skilled did withdraw from the labour force thus reducing the labour supply and thereby helping to maintain their relative wages. Also the growth in tertiary educated workers may have outstripped the demand over this period and the quality of graduates may have also falling, both putting downward pressure on the earnings of graduates. Partly as a result of increasing education of women the gap in total earnings of men and women decreased over the period with the real hourly earnings of men falling, those of women increasing by 10 percent.

Dixon noted that the increasing inequality in individual earnings came not from differences between identifiable groups but from increased differences within gender, age and education groups. In the case of age for example it was the inequality within in the 40 plus age group which played a major role, and in the education groups it was males with university education who contributed most to the dispersion in individual hourly earnings.

This increase in differences within the main demographic and educational groups which Barry Martin also found was most significant in his investigation of income inequality 1986 - 1991. By 1991 incomes - as measured by the census - had become more unequal than at any time in the post-war period, due primarily he argues to higher unemployment.

In a closely related paper Ben Amy also uses census data this time to assess the impact of employment restructuring on the Maori family whose incomes were particularly affected by corporate restructuring and the associated unemployment.

\section{New geographies of labour market disadvan- tage}

Communities in different parts of New Zealand also fared quite differently over the last two decades. Regional differences in income the associated access to employment widened significantly, particularly between the metropolitan centres and rural New Zealand. Levels of inequality also became more marked within metropolitan centres themselves and access to resources became more closely associated with residential location, mirroring patterns of social polarisation documented overseas. The attention at this conference was on the processes and consequences of these new geographies of employment.

Faced with the increasing geographical concentration of the jobless within metropolitan centres in particular Andrew Coleman hypothesises that once benefit levels or aggregate unemployment rates change beyond certain levels or thresholds there is rapid clustering of the jobless into particular areas, and, once this clustering happens, working people tend to leave. The essence of his model is a tradeoff individuals or households are believed to make between the consumption of ordinary goods and services and the consumption of the location externality (eg. schools and neighbourhood amenities). The jobless will typically choose to consume less of the location externality than the employed in part because they less income and in part because their transportation requirements differ. The presence of poverty traps and their implications for their rejoining the workforce are major reasons for policy attention to these questions.

Fraser Jackson picks up the same point drawing this time on Malinvaud who sees jobs being rationed among a competing set of job seekers. Queues develop and the labour market is 'cleared' according to Malinvaud through the rationing process. The ability of employers to vary wages in the short term is clearly limited but they have greater flexibility in substituting women for men, younger workers for old, parttimer for fulltime workers, or to redefine some jobs altogether. What this model implies therefore is that there may be major changes in labour force participation even though there is little change in wage rates. The disequilibrium created appears as a change in the unemployment rate or as additions to or withdrawal from the labour force rather than a change in price (wages).

Jackson's aim is to test such a model and he is able to show - assuming labour supply to be relatively inelastic - how changes in numbers in each occupation exceed changes in income in a manner consistent with the rationing model. $\mathrm{He}$ also draws our attention to the considerable degree to which income change in any electorate can be accounted for statistically by change in the occupational mix, much of which is determined by production technology. Occupational structure at the electorate level he argues permits "remarkably accurate pictures of the regional pattern of mean incomes" and "changes in the occupational structure of the work force....are sufficient to describe a high proportion of the variance of the change in mean incomes within electorates over time".

Philip Morrison notes in his paper how the persistence of unacceptably high unemployment levels which persist throughout the OECD has lead to greater attention being paid to differences in the way regional labour markets adjust to both growth and recession. He notes that when regional differences are raised for public discussion in New Zealand it is the geographical variations in the unemployment rate that often receive attention. However unemployment is merely the surface phenomenon of a condition which is much more deeply embedded in the geographical areas affected. Morrison constructs a regional labour market profile which, when applied to the 1991 census, shows that 
regions with high unemployment rates also experience low labour force participation rates; that when the labour force in such regions do find work they work fewer hours, and even when workers find fulltime employment their levels of remuneration are lower than in the more buoyant regions. The net impact is a correlated set of conditions which cumulatively incomes of those in the weaker regions.. The result is a closer association between location and disadvantage.

After becoming aware of the growing association between location and labour makret disadvantage the Prime Minister's Task Force on Employment in 1994 proposed a set of Local Employment Initiatives. There have been numerous local responses taken throughout New Zealand to address both high levels of unemployment and low participation rates. Anne de Bruin argues that given the continuing labour market disadvantage of ethnic minorities in particular, strong efforts are required at the grassroots level to create employment. But this is not easily done as De Bruin documents using an example in Otara. This community not only sought to address high levels of Maori and Pacific Island Polynesian unemployment but did so through an attempt to market their 'cultural capital'. She describes the way in which a number of projects were developed by Enterprise Otara to harness "cultural and ethnic riches" to create Otara as an attractive visitor destination. Of special relevance is the collaboration between 'outsiders' and the community in an attempt to combine an existing rich cultural capital with the professional and managerial skills necessary to allow it to be realised commercially. The project was designed to show that local initiatives need not be confined to small scale affairs but could actually lead to a significant large scale creation of meaningful employment. Despite considerable progress and some notable successes, after three years the project remains largely dependent on governmental funding for its continued existence.

Tony Bullard reports on a project which also has an explicit geographical and community focus. The Te Whanau o Waipareira Trust provides a large range of health, education, social, justice, economic and employment services to its predominantly West Auckland Maori constituency. It operates over a large number of sites and use a wide range of networks, alliances and joint ventures to deliver its services. Some 70 people in total are employed fulltime in providing these services plus about 200 others who provide regular voluntary work. Many see their work as building a future for their children, their mokopuna and generations to come - "it is not so much a job as a lifestyle but one with low remuneration and high staff turnover". The majority of Waipareira's services are funded though contracts won from contestable funding pools but they remain seriously under resourced. To deliver on its mission and to manage its operations, Waipareira typically holds some 92 meetings a month throughout the whole organisation and its membership including hui dedicated to specific issues. Within the organisation upskilling and multiskilling Maori is a part of the vision of Waipareira for Maori in general. The organisational model they have adopted in West Auckland draws on the traditional concept of whanau. It is their attempt to reproduce the sense of community, belonging aroha, support and associated principles of whanaungatanga to urban Maori.

Sean Bevin shows that, compared to the 1970 s when local authorities were encouraged by central government to undertake job creation programs employment initiatives have became more discretionary and linked more closely to the promotion and the facilitation of economic development initiatives. Today there are between the New Zealand Employment Service, Community Employment Groups, Be your own Boss programs and TradeNZ. Local authorities vary considerably in their degree of involvement in employment creation ranging from minimalist involvement to being quite proactive. Nevertheless there appears to be a chronic funding shortage and a lack of continuity in funding together with a perception that central government is insensitive to regional variations in both labour market performance and local economic growth.

\section{Demographic impacts on the labour market}

The first of these five papers is by Richard Bedford, Jacqueline Lidgard and Joanne Young who examines the relationship between international migration and the age structure of the labour force over the period 1991-1996. They show that international migration was a major contributor to what was the largest intercensal increase in New Zealand's population since the early 1970s. These net gains in the population were the result of a complex interplay of in and out migration. The central point the authors make is that these two flows have quite different impacts on both the ethnic mix and the age structure of workforce. Using arrival and departure data they are able to show that while citizens from countries in northeast Asia in particular have made the largest numerical contributions to net gains in 'other citizens' in all but one of the age groups have gains exceeded 50 percent of the total recorded for citizens of other countries. It was only in the $15-$ 24 age group that these exceeded half ensuring that the youthful labour force has not experienced the numerical declines that might have occurred as a result of the emigration of New Zealanders themselves. In the mediatric and older labour force groups international migration has augmented growth patterns and is contributing, in the longer term, to the progressive ageing of the New Zealand population.

In their study of 42 recent immigrants from Hong Kong, Taiwan and South Korea in 1995 Elsie Ho and Jacqueline Lidgard address the gap between immigrants expectations and the reality of the New Zealand job market. Most of the males immigrants were their forties, half had tertiary education, and were employed before coming to New Zealand. After immigrating to New Zealand nearly half the men and almost three quarters of the women found themselves without a job. Not surprisingly many of the men returned to their homeland and remitted funds from there. Of the women, most experienced 'downward' mobility in their work. In short recent Asian immigrants to New Zealand experienced occupational dislocation, marked reductions in income as well as separation of family members. None of these experiences contributed to their successful adaptation to 


\section{New Zealand.}

In a related paper Elsie Ho and Yunn-Ya Chen turn their attention to post-school employment choices of East Asia adolescent migrants. Their survey of schools in Auckland in 1995 revealed a strong wish to complete university education in New Zealand but considerable pessimism about their chances of local employment. The language barrier, racial discrimination and potential unemployment were cited as the main concerns about the job market. Not surprisingly over a third of males and nearly half the female students from Hong Kong wanted to return to home to work. This preference was also strong among the young women from Taiwan and South Korea but over eighty percent of men it appears were willing to try other countries. Few wished to remain in New Zealand. For these immigrants New Zealand was a place for education not employment.

The fourth paper on the relationship between demographic trends and the labour market focused on the close link between labour force participation and the timing of children. A. Dharmalingam, Ian Pool and Kim Johnstone show through their survey that the number of years a woman has worked is very closely associated with the timing of her first child. They found that working actually increases the chances of having a child, but as the work experience lengthens so this chance declined. It is the apparent direction of causation which strikes the authors - a women's decision to work apparently influencing her decision to have a first birth. It appears that not only is work important for each of the life cycle events separately, but it is also possible for work to have cumulative effects on the entire process of family formation.

The fifth paper by Roger Tweedy and Keith Johnson of the Mature Employment Service makes the point that although unemployment among mature aged adults ( $45-60$ years) is not high ( 4.5 percent) it is nevertheless a relatively intractable problem to those who experience it. Sixty percent remain unemployed for more than six months and in these age groups the older the unemployed person the longer the duration of unemployment. A major factor in keeping mature aged adults in work is their tertiary qualifications. Those without find they have less than equal access to specific vocational education and training. The authors argue that the national training and qualifications framework should be adapted to encourage more on-the-job learning and accreditation by mature workers. Several other recommendations to the Prime Ministerial Task Force on Positive Aging are also reported.

\section{Employment Contracts and ECA}

Five papers addressed the workings and measurable consequences of the Employment Contracts Act. In a deliberately provocative paper Brian Easton begins by questioning the evidence others have used to argue the benefit of the act. Specifically Easton argues that the poor productivity growth since 1991 casts doubt on the likelihood that the ECA was a major contributor to the macroeconomic expansion of the mid 1990s. In fact he argues that the act probably contrib- uted to poor real wage growth and the failure of many workers to obtain a share in the increase in prosperity of the 1990s. Rather than continuing to look for evidence of ECA effects at the macro level Easton suggests we turn our attention to what is happening at the worksites. We need to carefully examine whether the additional managerial freedom which the ECA allowed has resulted in new productivity inducing work methods as opposed to simply restricting growth in wages and other forms of remuneration as ways to cut costs.

It is to such workplaces that Peter Brosnan and Pat Walsh turn their attention. Focussing on the incidence and distribution of non-standard (not permanent and fulltime) forms of employment since the introduction of the ECA in May 1991 they conclude that the act has not had the labour flexibility effects proponents argued it would. There has not been the growth in part-time, fixed-term, temporary or casual employment which many predicted nor the substitution of contractors or consultants for employees although the private sector did increased its hiring of casual staff. On net, the proportion of permanent employees remains above two thirds of the workforce and casual employment has actually fell (from 8 to 5 percent of the workforce between 1991 and 1995. Meanwhile while fixed term employment has increased.

Research on the impact of the ECA at the macroeconomic level and at the work site is complemented by Rose Ryan's research on the hotels and restaurants sector. The hospitality industry has been used in the past to illustrate how employers make use of new-found freedoms to exploit workers in a disadvantaged labour market position. Ryan found from her survey of 560 establishments that the ECA has not resulted in an increased amount of real negotiation in this industry. The pattern of labour relations remains one of benevolent paternalism. Although usually written, employment contracts were frequently little more beneficial than required by legislation. Irrespective of whether the contracts were collective or individual, the prevailing patterns was for managers to determine the content of the contract, often after consulting with outside advisers. By contrast employees in this sector showed little awareness of their rights or possible sources of independent advice.

In another approach to assessing the Employment Contracts Act Craig Armitage reviews the Department of Labour's surveys in 1992 and 1993 which showed that many of the changes occurred in its initial years: the spread of enterprise bargaining and individual employment contracts and the concentration of these changes among the larger enterprises.

Preliminary results of the Department's 1996 survey of employees and of enterprises in November 1996 confirmed the impact of the ECA on enterprise bargaining al thoughmany employees appeared unaware of written versions of their contracts. Relatively high levels of ignorance over the presence of individual vs collective contracts were also exposed. As found in the previous surveys smaller enterprises were more likely to be based on expired awards or collectives and as such were far less likely to have been 
involved in negotiations for new or renewed employment contracts.

As a reflection of the increased importance of (private sector) casual work in the 1990s the Conference held a special workshop on the legal implications surrounding the status of the causal worker. Led by Judith Ferguson, the workshop focussed on the legal access casual workers have to personal grievance procedures and, by implication, the right to fair and reasonable treatment from an employer, particularly at the end of the employment relationship. The uncertainty surrounding the status of casual workers highlighted the contradictions inherent in the Employment Contracts Act itself. As Ferguson points out, although it is an Act designed to promote efficiency and flexibility through a free market contractual process, it still retains the traditional protections for workers incorporated in the personal grievance procedures now extended to all employment contracts. The workshop discussed cases which had been the bases of personal grievance claims brought before the Employment Tribunal. These illustrated the Tribunals desire to achieve some sort of fair resolution rather than an outcome determined by the application of a strictly consistent theoretical analysis. What mattered was what happened in practice rather than any label such as casual which had been used. Having said this the workshop concluded that while there were some reassurance to be had from the way some grievances were treated in specific situations, overall the prospects of casual workers having access to fair treatment under the Employment Contracts Act were not encouraging. Certainly the label 'casual worker' is not helpful and it would be in the interests of employees to have it removed altogether.

\section{Employment relations and human resource management}

The papers in this section dealt with four separate issues: human resource management as a discipline, occupation safety and health legislation and leave entitlements and international labour standards.

Joanne Cullinane argues that Industrial Relations and Human Resource Management (HMR) although institutionally quite distinct fields are in fact simply different views of the same set of phenomena. Her papers focus is on human resource management as a discipline and as a discourse. Cullinane argues that, given that HMR is a tool of management in capitalist society, the place to start pursuing a critical definition is at the level of political economy in general and regulation analysis in particular. Capitalism is inherently unstable and prone to collapse and therefore requires modes of regulation to support and define the capitalist superstructure. Cullinane draws our attention to the dominant regime, Fordism and how when the crisis of Fordism hit New Zealand massive restructuring occurred at all levels. We are still developing our own particular mode of accumulation typified by the Employment Contracts Act. As elsewhere there is unlikely to develop any single form of employment governance or labour process to replace Fordism, therefore HMR has become an umbrella term to describe a number of distinct approaches to employment governance.
John Wren looks at an one particular transformation of the regulation of the work environment in New Zealand - the occupational, safety and health (osh) legislation. By 1992 a new system of Employer Hazard Management had replaced earlier more centralised arrangements. The conscious adoption by big business and senior government officials of a philosophy of intervention and the adoption of risk management systems was significant because it represented a clean break from dependence upon overseas legislative models. Osh was considered an integral component of the 'industrial relations system' by both National and Labour and was consciously designed to be compatible with the industrial relations framework established in the Employment Contracts Act 1991 and the accident compensation changes of 1992.

Erling Rasmussen reports on the Danish experiment with three leave schemes: education leave, childcare leave and sabbatical leave, none of which are as generally available in New Zealand. Although extremely popular with employees in Denmark because of their generous provisions, employers were less enthusiastic largely because of the adjustments they had to make to replace staff on leave. Initially designed to open up opportunities for the unemployed, the latter did not benefit to the degree expected. Indeed the reduction in incomes associated with the schemes favoured those most able to absorb the drop in pay. For similar reasons opportunities leave provided for further education were least likely to be taken up by those who most needed them. The distribution of costs and benefits of such schemes make sobering reading for those who might advocate an extension of such schemes in New Zealand.

Nigel Haworth and Stephen Hughes argue that with the growth of international regulation of capital in recent years labour is in a position to press for the international imposition of core labour standards. They review a long literature which asks whether there is an international labour movement which is going to be able to mount an effective strategy against internationalised capital. They argue that regional trading blocs provide an opportunity for the extension of labour rights into an otherwise hostile environment. Such extensions may be applicable in the Asia-Pacific region and the paper looks ahead to the implications for New Zealand of APEC regional integration. They argue that the identification of a set of core labour standards constituting basic human rights implies the potential for a universal acceptance of these rights in the context of economic development which they hope will transcend cultural particularities.

\section{The management of employment}

Part 7 of the conference dealt with the management of employment and involved a number of highly instructive case studies covering a variety of businesses, the university, the health sector and the meat industry.

Disputes within the workplace are more likely to occur in certain types of business structure and management practices.. Drawing on cases accumulated since 1994 by the 
Waikato Mediation Services Stephen Hooper argues that in order to address workplace disputes it is essential that the context within which the dispute arises be carefully considered before any action is taken by employers. Four factors appear important: hierarchical structures that limit communication between management and staff, entrenched cultures of managerial decision-making as opposed to consensus decision-making, a climate that promotes independence and self-reliance at the expense or 'teamwork' and a culture of avoiding or suppression of conflict. Given these factors it is essential to review the effectiveness of early intervention in organisational disputes as opposed to mediations that take place after the grievance has already occurred.

Michael Pye and Joanna Cullinane explore the contemporary research needs of a sector which has seen its fare share of conflict following considerable political, legislative and managerial change since 1996. Their survey of 19 health organisations identifies five distinct areas where research is needed: workforce development and planning, employment contracts (their nature, scope and negotiation), how to best manage groups of professionals, how to relate to external organisations and the effect of future uncertainties on present employment relations. They observe that the 'new' health enterprises, the staff, their unions and professional organisations entered the new era with no organisational or sector history of anything other than the 'old' style of management. As a result they had to face serious longstanding financial constraints with little opportunity to plan for a process of change.

Rupert Tipples and Branka Krivokapic-Skoko consider the importance of the psychological contract in employer-employee relations. Based on an analysis of academic staff at Lincoln University they examine how staff are weighing the new reality of university working life against the expectations that lead them into academia in the first place. The primary cause for complaint would appear to be the growth in University administration which is being perceived as unproductive, formalistic and bureaucratic and which has, with increased explicit measures of accountability, undermined previous feelings of trust and collegiality. The perceived shift in power from academic to administrator would appear to have upset the basis for the psychological contract.

In findings which complement Stephen Hooper's study of personal grievance disputes, Ramzi Addison shows how high failure rates of change initiatives (such as TQM) can be traced directly to the quality of employment relationships prior to the change. With respect to the four meat plants Addison found that a 'positive' prior context characterised by such factors as high trust relationships, mutual respect and high delegation was more likely to lead to a successful outcome than a 'negative' prior context characterised by such factors as autocratic management, low trust and low mutual respect. Prompted by unexpected high costs of new chain technology, this study was able to relate these additional costs to deficient implementation and human resource management processes. This underscores the more general finding in the literature that the reasons for the failure of
Total Quality Management and the later Business Process Reengineering stem from a lack of commitment by senior managers and inappropriate human resource practices. The social subsystems of organisations clearly play a critical role in implementing change and Addison's research confirms previous studies which show large differences in conflict levels between otherwise similar meat plants can be attributed to the quality of management rather than the militancy of the unions.

In a second study of the meat industry Bruce Curtis explores the reasons Fortex failed. Liquidated in 1994, Fortex can be said to have fronted an effort to rework the networks of the meat industry and although the firm obtained the close support of the meatworkers' union in its plants it was nevertheless undone by an alignment of interests outside the firm, notably the farmers as suppliers of stock. The failure is instructive in pointing to the limits of innovation ('the Fortex way' in this case), the role of networks in the industry and how the very successes secured 'inside' Fortex ended up making it extremely vulnerable to the supply decisions of farmers.

\section{Human development}

In the first of three papers in this section Maria Humphries and Bev Gatenby seek to broaden the definition of 'career' to mean the pattern of work-related experiences that span the course of a person's life. Their aim is to shift attention from the traditional definition of career based on organisational dominance to one defined by the individual over the life course. While recognising a shift in attention by some research away from categories of difference towards a celebration of the individual and empowerment these authors caution against the 'politics of optimism'.

The authors apply longitudinal, feminist participatory action research to the experience of women, broadening of the notion of career to include caring for home, family, relationships and communities. Feminist critiques of employment point to the rather more 'disorderly' lives of women compared to the ideal (male) characters upon which traditional career models were based. Reports from those women participating in the project illustrate the struggles they have in finding a durable definition of 'career' which suits their multi-dimensional lives.

Challenging the meaning of terms which hold such a central place in the literature is also the purpose of the paper by Cushla Paice, Carl Davidson, Hilary Bennett and Mike O'Brien. They examine the nature of work and how it varies across workplaces of different size and competitive environments. The authors draw on their research in 19 Auckland workplaces to reveal a number of serious definitional, theoretical and methodological problems. With an explicit focus on small businesses their aim was to get matched workplace (from employer) and employee data but they encountered considerable difficulty with terms like casual work, contractors, and employment contracts. Arbitrarily drawing a line between groups as has been previously done say in reference to 'standard' work is no longer appropriate 
they argue. Although carrying considerable cost implications face-to-face interviews do appear to have considerable advantages. They tend to be preferred by respondents who are therefore more likely to respond and it also helps remove the burden of 'questionnaire overload' which now afflicts small and medium sized businesses.

Pat Reid's research on paid work and intellectual disability draws on responses by fourteen workers on how they obtained and learned their job and the initial and on-going support they received. Ranging in age from 24 to mid 40 s and most intellectually disabled workers had part-time work, constant hours and were officially categorised as having elementary occupations: cleaning, delivering goods etc. They were highly motivated and aware of the need to take the opportunity to work. Far from being unemployable their reasons for and motivation to work of this sample group mirror those of the general population. They wanted to earn a living, valued their jobs and wanted the chance to progress to more hours and greater challenges so they could get real pay for real jobs.

\section{Statistics}

The two papers in part 9 of these proceedings deal with developments in labour and employment statistics. Brian Easton reviews the late Brendan Thompson's legacy of historical workforce statistics. Easton lists the available series and shows how he has applied a number of them in his own work. Thompson's series provide a sound quantitative basis for those concerned with the aggregate and structural change of New Zealand over the last 160 or so years, and as Easton's own illustrations highlight their use and help secure them an important place as a source for research on the economic and labour histories of New Zealand.

The final paper in these proceedings contains an update on the labour market statistics which Statistics New Zealand has provided since the first of these LEW conferences in 1984. Ian Ewing and Sharon Evans point out that largely due to funding shortages official statistics have not kept pace with the deregulation of the labour market in the 1990s. They are able to list a number of important advances in the last few years: these include the extensions to the education and training topics in the 1996 census of population and the adding of a supplement to the Household Labour Force Survey on education and training (once only) and income (annually). In addition feasibility studies funded by a group of government agencies have been undertaken on employer's training practices and expenditure and Statistics New Zealand has develop new classifications for levels of educational attainment and field of educational study.

\section{Acknowledgements}

A draft of this overview was circulated and I wish to thank Paul Callister, Sylvia Dixon and Roberta Hill for making suggestions particularly about the directions of future research. I have freely included their suggestions in the above. I also wish to thank Jam's Typing Service for their excellent word processing work. 